\title{
La cultura de los sepulcros de fosa: una sociedad neolítica
}

\author{
Ana M. ${ }^{a}$ MuÑoz Amilibia*
}

\section{RESUMEN ABSTRACT}

Se argumenta el caracter de sociedad plenamente Neolitica del grupo conocido como "cultura de los sepulcros de fosa" fechado entre 4300 y el 3100 antes de Cristo, en dataciones calibradas, en un momento de pleno desarrollo del neolítico europeo.
This paper contributes a critical review in order to show the "sepulcros de fosa" culture as a clearly neolithic society, dated from 4300 until 3100 B.C., during the highes improve of European Néolithic.

No sé si tras el título elegido podrá adivinarse mi intención. Calificar de la forma más gráfica posible lo que representa un contexto arqueológico muy concreto, conocido desde hace más de sesenta años precisamente por una documentación muy llamativa, plenamente arqueológica. Una documentación que transmite un mensaje muy claro y nos pone en contacto con la representación de una sociedad verdaderamente neolítica.

Después de más de treinta años (Muñoz, 1965), me ha parecido que podría ser interesante retomar el tema de los sepulcros de fosa con una visión actualizada, tratando de definir el grupo como una sociedad neolítica, lo que conlleva también mi definición de lo que considero una sociedad neolítica. En realidad, esta intención no es nueva. Mi buen amigo el profesor Tarradell, que tan bien planteó esta cuestión con sus "pagesos del plá» (Tarradell, 1962, págs. 71-97), me sugirió que preparara un artículo para la revista Fonaments con motivo de cumplirse veinticinco años de la publicación de mi tesis sobre el tema. Me pareció muy bien la idea, ya que

* Catedrática de Prehistoria. UNED. 
sólo había vuelto a tratar los «sepulcros de fosa» de forma muy general (Muñoz,1983, págs. 52-60). No me fue posible hacerlo entonces, y, posteriormente, sólo me he referido a ellos de forma tangencial (Muñoz, 1996 y 1997). En esta oportunidad, me propongo hacer una breve síntesis del estado de la cuestión y mis puntos de vista, dedicándolos a la memoria del Dr. Tarradell.

Son muchas las aportaciones que se han hecho en tantos años. Sin duda la más importante ha sido la documentación de su actividad minera, gracias al enorme esfuerzo - a veces olvidado- de unos jóvenes arqueólogos de la Universidad de Barcelona, que insistieron una y otra vez en el estudio de la explotación minera de "calaita» de Can Tintorè en Gavà, a pesar de las dificultades que entrañaba por la escasez de medios con que contaban. Desde Murcia seguí la marcha de los acontecimientos, la preocupación del Dr. Maluquer por los peligros que corrían sus alumnos excavando las galerías mineras sin la protección necesaria. Quizás este recuerdo quiera compensar el que, a pesar de la distancia a que me encontraba, no les ayudara tanto como merecían. Incluso me proporcionaron una pequeña muestra de "calaita» para ver si me la analizaban en algún laboratorio de la Universidad de Murcia. No conseguí que lo hicieran, pero lo increíble es lo que tardaron ellos en lograrlo. Una prueba más de las dificultades y poca atención con que contaron y que, afortunadamente, no les impidió seguir adelante. Lo importante es que lo consiguieron, culminando el estudio con la magnífica publicación, que tanto ha enriquecido nuestro conocimiento de la población de los sepulcros de fosa (Villalba, y otros, 1986). En la actualidad, el estudio de todos los aspectos que ofrece esta minería neolítica, es uno de los objetivos principales de la investigación en torno a los "sepulcros de fosa". La elección de Gavá, en 1995, como sede de la celebración del I Congreso Internacional de Neolítico de la Península Ibérica, es en cierto modo un reconocimiento más de su importancia (Actes I Congrés del neolitic..., 1996).

También son importantes la serie de excavaciones que permitieron confirmar, con secuencias estratigráficas y dataciones absolutas, la situación diacrónica del desarrollo de la cultura (Baldellou y otros, 1975; Martín, 1982; Martín, Guilane y Thommeret, 1981), así como la continuidad de las excavaciones en yacimientos como la Bóvila Madurell y otros de su entorno en lo que se había llamado Sant Quirçe de Galliners (Llongueras y otros, 1981; Martín y otros 1988; Pou y otros 1996). Muy importante fue también la esperada publicación de las ricas y "clásicas" necrópolis de Sant Julià de Ramis y del Puig d'En Roca en Gerona con un estudio antropológico póstumo de Fusté de gran interés, aunque no pudiera abarcar el de todos los restos de las necrópolis (Riuró y Fusté, 1980). 
Posteriormente se han publicado otros hallazgos que amplian el espacio geográfico de los sepulcros de fosa, no sólo hacia la desembocadura del Ebro y Castellón por el sur, sino hacia el curso del Ebro con los hallazgos de Mequinenza, que parecen marcar "la ruta de la calaita» hacia la Meseta, y hacia el Pirineo hasta Andorra.

Un buen resumen del estado de la cuestión es el que hizo Vicente Baldellou en el Homenaje al Profesor Maluquer, celebrado en Zaragoza en junio de 1990 (Baldellou, 1992). Comparto su opinión de que la cultura de los Sepulcros de Fosa, calificada generalmente como Neolítico medio en los actuales esquemas catalanes, cronológicamente debe enmarcarse en "unos términos más avanzados", representando una transformación total de los registros arqueológicos anteriores, una fractura brusca de los componentes tecno-culturales anteriores, "con la irrupción de la nueva civilización». En cambio, Araceli Martín —sin duda una de las mejores conocedoras de los «sepulcros de fosa»- sigue manteniendo la fragmentación del Neolítico en antiguo, medio y reciente, y dando especial protagonismo a las facies Molinot y Montboló (Postcardiales), como antecedente de los sepulcros de fosa (neolítico medio), incluyendo en el Neolítico finalCalcolítico, la facies Veraza (Martín 1992a y 1992b), reduciendo cada vez más el espacio cronológico y geográfico de los sepulcros de fosa (Mestres y Martín, 1996).

Mi opinión es que no sólo las dataciones absolutas colocan «en su sitio", en el neolítico reciente, la cultura de los sepulcros de fosa, sino que su propio contexto cultural permite encuadrarla en el proceso general de transformación de los grupos neolíticos europeos, con la adquisición de nuevas formas de vida, de amplios mecanismos de interrelación, nuevas tecnologías y enfoques ideológicos. Por eso, ya desde los comienzos de la investigación, los sepulcros de fosa se equipararon a los grupos Chassey, Egolzwill-Cortaillod o Lagozza, representativos de neolítico reciente de Europa Occidental. Este proceso, se inició y definió, de forma casi simultánea, en un amplio espacio geográfico, a lo largo, más o menos, de un milenio, entre el 4300 y el 3100 A.C., aproximadamente, en fechas calibradas para los sepulcros de fosa. Esta es para mi la característica principal del grupo de los "sepulcros de fosa" - bien definido desde los comienzos de la investigación prehistórica en Cataluña-, su carácter de "Sociedad neolítica plenamente formada», madura, diversificada y sólidamente establecida durante un largo período, $y$, al mismo tiempo, conservando su personalidad entre otros grupos vecinos contemporáneos. En realidad, la adscripción de los sepulcros de fosa al Neolítico Medio, se debió en gran parte a los vasos de boca cuadrada, más bien escasos en los sepulcros de fosa. Eran los años 1940-50, en que se fue conociendo la 
estratigrafía de Arene Candide, incluso directamente por las conferencias y cursos impartidos en Ampurias y Barcelona por su excavador L. Bernabò Brea. Maluquer divulgó estos descubrimientos y llamó la atención sobre los vasos de boca cuadrada que, en Arene Candide correspondían al Neolítico medio, en relación con los sepulcros de fosa, aunque diferían mucho desde el punto de vista tipológico, y el propio Bernabò Brea no veía clara la relación entre los vasos españoles y los danubianos. En realidad, lo que destacaría de nuestros vasos de boca cuadrada, es su novedad desde un punto de vista funcional como plato o fuente para servir seguramente un nuevo tipo de alimento, una mezcla a base de harina o cereal, algo espesa. Es el antecedente de los platos y fuentes tan típicos del Calcolítico y de sociedades con nuevos hábitos de relación social o familiar a la hora de las comidas. La rica y variada vajilla de los sepulcros de fosa, va desde los recipientes de almacenamiento, las ollas, los cuencos y tazas para beber, de uso individual, hasta las fuentes de carácter colectivo. En este, como en otros muchos aspectos la cultura material refleja una profunda evolución social. Bastaría recordar la peculiar industria de silex y su calidad, silex melado, cuya procedencia se ha querido ver en Provenza. O las magníficas y «nuevas» hachas pulimentadas, tanto por la técnica de elaboración, como la materia prima, por no volver a referirme a la calaita. Estoy de acuerdo con Manuel Edo en que conviene conservar la denominación, más precisa que la de «piedra verde» desde un punto de vista arqueológico, cuando no se dispone de análisis concretos.

La definición de un grupo humano como neolítico es evidente que no puede hacerse en función de sólo una determinada variable cultural -como podría serlo en el orden tecnológico la cerámica o la piedra pulimentadasino de una transformación global hacia el modo de vida campesina, lo que conlleva cambios profundos en su vida social y espiritual. Una de las variables culturales más importantes es el agrupamiento de una población, reunida por la comunidad de intereses sobre un territorio o espacio geográfico concreto. La explotación de un territorio supone la necesidad de instalarse en él mediante un asentamiento de carácter permanente en un poblado o de carácter estacional en campamentos o instalaciones renovadas en el mismo sitio. En los sepulcros de fosa, son muy escasos los restos de habitación, los supuestos "fondos de cabaña» o pozos de residuos, basureros, «fuegos" - testigos de su estancia- documentados en algunos casos. Así, en la Bovila Madurell, donde algunos "fuegos" proporcionaron además fragmentos de cerámica con decoraciones tipo Chassey y dataciones calibradas de 3709-3372 A.C. Una datación aún más antigua (3946-3531 A.C.), tenemos para el poblado — situado a más de $1300 \mathrm{~m}$ sobre el nivel del mar- de la Feixa del Moro (Juberri, Andorra), 
donde se han hallado algunas semillas de cereal, pero no restos de fauna doméstica ya que hasta los punzones se han trabajado sobre huesos de ciervo.

La instalación permanente servía además para reafirmar la propiedad de un territorio por parte de una comunidad, que tenía que ir adquiriendo, necesariamente, una organización social más compleja. Desde la distribución ordenada del espacio de habitación y explotación, a los de almacenamiento y necrópolis. En la Bóvila Madurell, como en las de Padró y Bellsolá o el citado poblado de la Feixa del Moro, los lugares de habitación parecen coincidir con los de enterramiento. Aunque la larga historia de uso de la Bóvila Madurell, y las diversas etapas por que han pasado sus descubrimientos y estudio, hacen difícil precisar la extensión del poblado y su relación espacial y cronológica con las sepulturas, parece que hay que pensar en grandes asentamientos de más de 30 ha., aunque no se conserve el suelo original. Sólo han sobrevivido fosas o cubetas cortadas por las labores agrícolas posteriores y seguramente las cabañas se construyeron con materiales perecederos, aunque se haya podido estudiar alguna estructura de habitación (Martín, 1992a, 326-327)

La vinculación al territorio, esta marcada sobre todo por su presencia real, individualizada, en las necrópolis, en las tumbas trabajosamente excavadas a bastante profundidad como para que hayan podido llegar hasta nosotros. Hoy en día, conociendo su capacidad para excavar pozos y galerías mineras, no nos sorprende que excavaran sus tumbas a tanta profundidad. A través de esta "arqueología de la muerte» tenemos que llegar a la de los vivos. Gracias a que las fosas estaban excavadas en terrenos arcillosos, con mucha frecuencia su hallazgo solía estar vinculado a la explotación de arcillas para tejerías o ladrillerías (bóvilas), por lo que los cortes verticales del terreno permitían localizar las sepulturas en profundidad. Esto hizo posible que personas beneméritas como Don Vicente Renom, Director del Museo de Sabadell, o Don José Estrada Garriga, del de Granollers (aunque estuviera más interesado por «los romanos»), dedicaran gran parte de su vida a seguirles el rastro, recogiendo una valiosa información que si no, se hubiera perdido totalmente. A ellos quiero también recordar, con agradecimiento, por su labor y también por su generosa colaboración.

Pero el terreno arcilloso permitió en muchas ocasiones la conservación de esqueletos, que, muy tempranamente, fueron estudiados por Miguel Fusté, y más tarde por Amparo Font, Daniel Turbón, Elisenda Vives y Oriol Mercadal. El estudio antropológico determinó en bastantes ocasiones unos caracteres físicos, algo distintos a los de los tipos «gráciles mediterráneos», 
propios del Neolítico mediterráneo peninsular. Estos rasgos, concretamente el a veces acusado prognatismo, los relacionaban en cambio con algunos presentes en esqueletos cromañoides paleolíticos (Grimaldi) o neolíticos de Suiza (Chamblandes, Egolzwill, La Barmaz sur Collombey). En pocas ocasiones, como señaló Fusté, se podía documentar concordancias entre elementos culturales y complejos raciales, aunque con su habitual rigor insistía en la necesidad de aumentar el número de datos, para poder llegar a conclusiones más concretas (Fusté, 1952, 1960; Riuró y Fusté, 1980).

Tenemos pues instalados a los hombres y mujeres de los sepulcros de fosa, que enterraban esforzada y generosamente a sus muertos, hombres, mujeres y niños, en fosas de distintos tipos, individuales, de pareja, o con el hijo, acompañados a veces de objetos valiosos, tanto útiles como ornamentales que, en general, podemos calificar como de «uso personal». Aunque haya diferencias en el ajuar de tumbas de una misma necrópolis, no me atrevería a pensar en grandes diferencias sociales, que incluso parecen marcar linajes desde el nacimiento (algunos ajuares infantiles), sino más bien destacar que la diferencia está sobre todo entre los distintos poblados, unos más ricos que otros. Esta es una característica muy importante en un grupo neolítico cultural y cronológicamente avanzado. La economía del poblado y su mayor o menor prosperidad, su riqueza, está en relación con su situación geográfica y los recursos potencialmente disponibles, que orientaban sus actividades agrícolas y ganaderas hacia la obtencićn de rendimientosos autosuficientes o incluso excedentarios que les permitiera mantener una comunidad reducida o de más altos vuelos demográficos. Es evidente que una mayor diversificación de recursos, con un soporte suficiente técnica y demográficamente, permitió a la población de los sepulcros de fosa superar el nivel de simple poblado campesino y hacerla capaz de embarcarse en explotaciones mineras de materias primas de carácter suntuario. $Y$, naturalmente, esta explotación llevaba consigo una producción manufacturera y una red de intercambios, que no serian simplemente comerciales sino de relación y comunicación con otros grupos, aunque sin perder su propia personalidad. La cultura de los sepulcros de fosa debía de ser muy superior a la de otros grupos vecinos, tanto desde un punto de vista cultural, como tecnológico y económico, aportando más que recibiendo $y$, por tanto, conservando sus caracteres propios, entre los que no es el menor el ritual funerario.

Estamos ante un grupo de población muy real, muy próximo y complejo, que no se puede reducir a una simple etiqueta de "neolítico medio», sobre todo cuando algunos posibles grupos que estos últimos años se han revalorizado en exceso, sólo se documentan por alguna variante tipológica 
de la cerámica (Molinot, Montboló) incluso con diverso ritual funerario (Veraza). El grupo de los sepulcros de fosa tiene suficiente entidad como para no estrechar sus límites, ni intentar resolver cuestiones como las de "sus orígenes" o «final». A mi juicio, es éste un aspecto muy importante que no se tiene demasiado en cuenta a la hora de establecer tantos grupos comarcales, que no tienen una entidad propia, sino que forman parte de un contexto cultural más amplio. Son problemas que actualmente, desde un punto de vista histórico, creo que tienen menos interés, y que en todo caso podrían abordarse a través de estudios paralelos con modelos culturales semejantes, como podría ser el grupo Chassey. Pienso que la cultura de los sepulcros de fosa, a pesar de lo mucho que va aumentando su conocimiento, está atravesando una crisis en su valoración y en muchos casos en la orientación de la investigación, a mi juicio excesivamente preocupada por los «estilos cerámicos».

También los prehistoriadores franceses parecen tener una tendencia a la fragmentación regional excesiva. El gran complejo neolítico «chasseense» va quedando fragmentado por la excesiva personalización de facies más o menos locales o "personales", que desfiguran la importancia y enorme difusión del grupo, por casi toda Francia (Demoule y Guilaine, 1986). Son en el fondo las consecuencias del radical rechazo al difusionismo, que, desafortunadamente, a veces dio lugar a un evolucionismo un tanto aldeano. Convendría recordar, dentro del merecido Homenaje que se dedicó al Dr. Jean Arnal (1907-1987), que fue él quien tuvo el mérito de ser el primero en poner de manifiesto la importancia del contexto Chassey, a lo largo de cincuenta años de investigación prehistórica en la región del Languedoc, donde ejercía su profesión de médico rural desde el pueblo de Saint-Mathieu-de-Tréviers (Hommage, 1988). Primero en excavaciones en cuevas como la de la Madeleine, donde estableció una secuencia estratigráfica, dando a conocer sus riquísimos materiales, luego en poblados al aire libre. Se ha dicho con razón que el Dr. Arnal, junto con el Abate Breuil eran los prehistoriadores franceses más conocidos en el extranjero, y podríamos decir que particularmente en España, donde sus publicaciones se divulgaron incluso en traducciones al español. En ellas destacaba sin duda su entusiasta interpretación difusionista, tan propia de la época, y, esta, junto con su carácter amateur, es posible que hayan sido causa de la reacción a que me he referido antes.

La dilatada cronología de los sepulcros de fosa, que se mantiene en calibraciones recientes (Martí, 1998, pág.157), desde las más antiguas de Can Tintoré (4357-3969 A.C.) a las más tardias de Sabassona (3092-2700 y 2873-2459 A.C.), explican sus contactos con otros grupos distintos, y, más aún, si tenemos en cuenta la nueva documentación que nos aportan las 
redes de distribución -y por tanto de contactos- de la «calaita» (Edo, Villalba y Blasco, 1992). El ritual funerario es muy específico, y él de la "calaita», debió de ser tan importante como en otros grupos europeos, entre los que destaca sin duda el bretón. Pero también reportaría indudables beneficios económicos. Su explotación, manufactura y difusión, debió de jugar un papel muy importante en la transformación de una sociedad neolítica avanzada, hacia una pluralidad de actividades, de más largo alcance que las propias de una sociedad simplemente campesina. No voy a entrar ahora en otro tema interesante, el de la búsqueda de piedras de color verde y el posible conocimiento de minerales cupríferos como la malaquita o la azurita, y su posible relación con los comienzos de la metalurgia.

Pero las minas de Can Tintoré han aportado otro interesante dato en relación con el mundo espiritual de los sepulcros de fosa. Se trata de la parte del cuello de una vasija decorada, reconstruido a base de fragmentos encontrados en mayo de 1994 en el relleno del pozo 16 de las citadas minas, que, al parecer, se había colmatado con residuos una vez terminada su explotación. Por tanto, son fragmentos cerámicos amortizados en el momento de abandono de esta parte de la mina. Tras la recomposición de los fragmentos, los descubridores publicaron la pieza con todo detalle y buena ilustración (Bosch y Estrada, 1995). La calificaron cómo figurita antropomorfa. Cómo he dicho antes, me inclino a creer que es parte de una vasija, del cuello y hombro de la misma, aunque no haya, de momento, ningún fragmento del borde. He tratado de hacer una reconstrucción provisional basándome en el dibujo de Ramón Alvarez en la publicación citada. Es posible incluso que la aparición de nuevos fragmentos confirme o rechace esta hipótesis (figura 1 ).

La cerámica es de pasta fina de buena calidad con superficies muy bien bruñidas y oscuras, de un tipo habitual en la cerámica «fina» de los sepulcros de fosa. El supuesto "cuello", podría medir unos $11,5 \mathrm{~cm}$ de altura conservada y unos $9,5 \mathrm{~cm}$ de diámetro, si aceptamos la inclinación que le dá el citado dibujante, ya que cómo he dicho, le falta el borde. Se conservan, en altura, unos $4,8 \mathrm{~cm}$ del hombro de la vasija en que su diámetro se ensancha considerablemente. Aunque en las tablas de formas cerámicas de sepulcros de fosa no son frecuentes los cuellos, hay piezas bitroncocónicas con la mitad superior retraída a modo de ancho de cuello, pero se trata de tacitas de unos $8 / 12 \mathrm{~cm}$ de altura, de los que la mitad, 4$6 \mathrm{~cm}$ aproximadamente corresponderían a la parte superior. Por eso, pienso en su posible relación con una jarra de almacenamiento, que en algunos casos, cómo en la sepultura de Aguilar de Segarra por ejemplo, es de pasta fina con engobe casi negro, fabricada en dos partes unidas por el centro, y con la parte superior de tendencia marcadamente inclinada hasta 

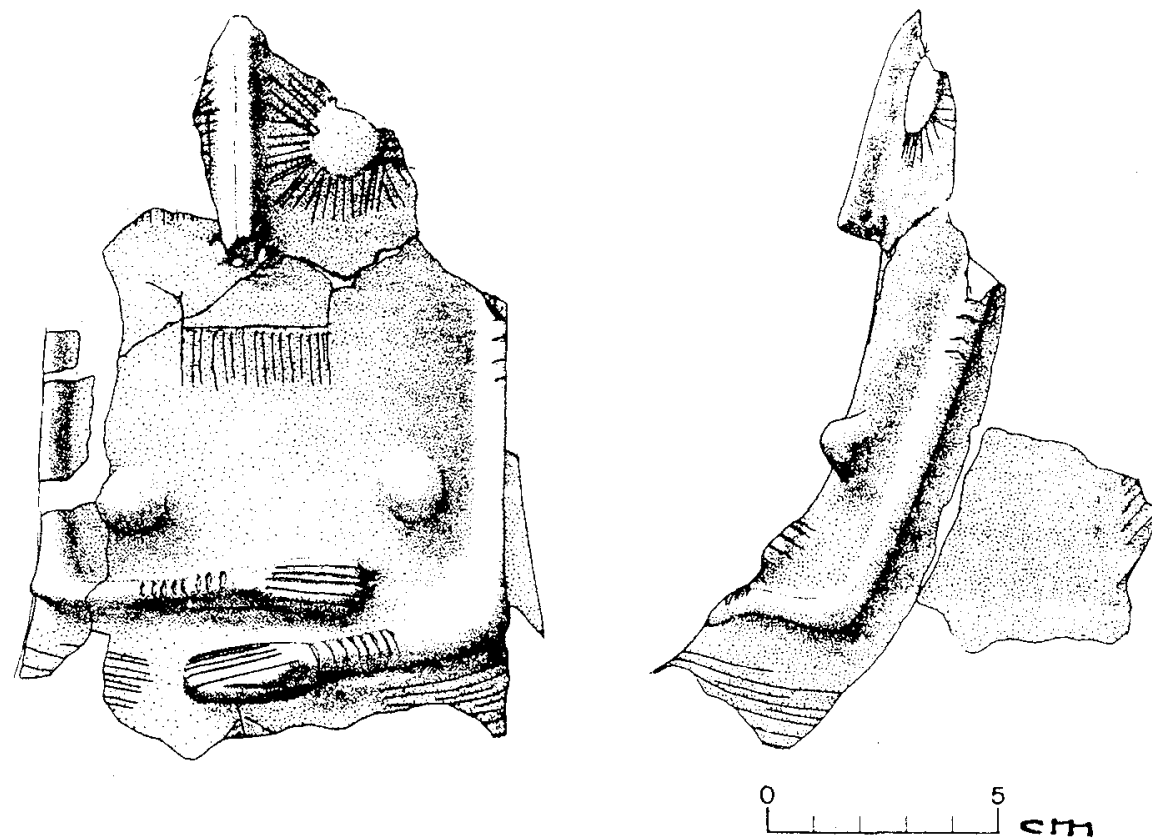

Figura 1. La "Dama de Gavà» (según Bosch y Estrada, 1995).

estrechar la boca en $12,8 \mathrm{~cm}$ desde el diámetro máximo de $30,5 \mathrm{~cm}$. La parte superior, sobre las asas, supone bastante menos de un tercio de la vasija, 10,2 cm de altura, que se aproxima mucho a la del cuello de la pieza que estudio.(Muñoz 1965, tipos 12-14 y 19 y págs. 138-139). De todas formas, en las minas de Can Tintoré el tipo de ollita bicónica Grupo $D$ - puede alcanzar dimensiones que se adaptan mejor a las del fragmento figurado (figura 2).

Pero lo más llamativo es la decoración plástica de esta vasija. Se trata de la representación de una "dama». La he calificado así porque impresiona su prestancia. Aparece erguida, algo apoyada hacia atrás, como entronizada, sentada, con los brazos junto al cuerpo, doblados por el codo en ángulo recto y las manos apoyadas reposadamente sobre el vientre abultado - coincidiendo con el ensanchamiento del cuerpo de la vasija-, que los editores han interpretado como indicio de embarazo, como las «diosas preñadas de la vegetación» de la zona balcánica, señaladas por Maria Gimbutas (Bosch-Estrada, 1994 y 1995, págs. 287 y 290). A mi, tanto por el soporte cómo por el carácter de «personaje», me recuerda más el de la famosa vasija pintada de Hacilar. 




Figura 2. Cerámica del grupo D de Can Tintoré (según Villalba y otros, 1986, lám. 36).

Pero no es mi intención buscar paralelos más o menos lejanos, sino tratar de analizar lo mejor posible este hallazgo excepcional en el ámbito del Neolítico de la Península Ibérica. La técnica decorativa empleada ha sido doble, modelado e incisión sobre la pasta dura. Los ojos, la nariz, los 
pechos y los brazos, están hechos en relieve, aunque todo ello, excepto los pechos, está retocado con esgrafiado. Ambas técnicas aparecen en la cerámica de sepulcros de fosa, además de la incisión, aunque predomina siempre la cerámica lisa (Villalba, Bañolas y Edo, 1991, págs. 23).

La «Dama» presenta una gran nariz en relieve, de recto y saliente perfil, y, a ambos lados, los grandes ojos soliformes - sólo se conserva uno casi completo y pocos vestigios del otro-, formados por discos o pastillas en ligero relieve, rodeados de finos y apretados rayos esgrafiados. No se indica la boca y si un adorno o collar, fuertemente grabado y muy bien centrado en relación a la nariz. Cuelga de dos líneas, curvadas en la parte superior, que sujetan una línea o travesaño horizontal, del que penden, sin unirse a él, quince líneas verticales a modo de flecos. Muy por debajo, y bastante separados, se indican los dos pechos en relieve, muy puntiagudos, como los pezones que tantas veces decoran las cerámicas. Desde los hombros y pegados al cuerpo, se señalan en relieve los dos brazos, muy delgaditos si los comparamos con la nariz, que se doblan por el codo apoyando ambas manos en el regazo, con un aire de solemnidad. Cada uno de los brazos está decorado por ocho líneas grabadas, brazaletes, que los circundan por encima de las muñecas. Las manos, también en relieve, son grandes pero finas y alargadas, con los dedos indicados por fuertes incisiones. Por debajo de la cintura, a la altura de las caderas, donde queda manifiesta la citada gravidez, series de líneas paralelas forman sendas franjas a cada lado, interrumpidas en la parte central, donde se adivina otro motivo inciso - un triángulo con la punta hacia arriba partido por una línea que sobrepasa el vértice- que podría ser una indicación del sexo, o más bien parte del adorno del vestido, a base de rombos quizás. No podemos saber si las franjas horizontales continuarían por detrás, alrededor del cuerpo, por estar rota la pieza. Otro fragmento cerámi$\mathrm{co}$, que parece corresponder a la parte posterior, según la restauración, presenta unas rayas incisas oblicuas, que es difícil relacionar con el resto.

Hasta ahora, no teníamos ningún hallazgo en el contexto de los «sepulcros de fosa", relacionable con una posible divinidad. La verdad es que seguimos acercándonos a este grupo sobre todo a través de sus tumbas y el ritual funerario. El conocimiento de las minas de extracción de Variscita Férrica, la piedra verde o "calaita», tan llamativa en los ajuares funerarios, ha sido de relevante importancia en el estudio de éste grupo, paralelizable con otros del Neolítico avanzado de "cerámicas lisas» de Europa occidental, no sólo el más próximo de Chassey, con el que comparte muchos elementos comunes. En otra ocasión (Convegno de Ozieri, 1990; Muñoz 1997), intentando buscar alguna relación entre el Neolítico sardo y el de la Península lbérica, me refería a los sepulcros de fosa con 
una estructura de acceso lateral, que podrían relacionarse con las sepulturas de Bonu Ighinu, e incluso a su capacidad de excavar galerías mineras aunque no fueran comparables a los magníficos hipogeos cómo los sardos. Sin duda nos faltaban las regordetas e insuperables estatuillas femeninas de la necrópolis de Cuccuru S'Arriu (Cabras), entre otras del mismo tipo. Ahora tenemos al menos una representación femenina dentro de una estética parecida.

Es arriesgado interpretar esta representación cómo una divinidad. Lo que si me atrevería a afirmar es que seguramente no se trata de una divinidad de carácter funerario. Aunque su hallazgo fue fuera de contexto, pienso que su vinculación a un posible recipiente de almacenamiento, indicaria más bien una protección de los vivos -o de sus pertenencias, agua y alimentos- encerrados en un mundo subterráneo con un trabajo muy arriesgado. Parece que es poco después cuando en nuestra Prehistoria empiezan a depositarse símbolos protectores o representaciones del mismo difunto entre las ofrendas funerarias de megalitos, cuevas sepulcrales, hipogeos. Y son precisamente entre estos símbolos, los ídolos-placa los considerados más antiguos -de mediados del IV milenio a.C- en los ajuares de megalitos y cuevas sepulcrales del occidente de la Península. Se trata de los primeros «ídolos oculados», que luego aparecerán en otro tipo de soportes: cilindros, falanges, huesos largos o rupestres. El tipo de ídolo oculado siempre se había considerado algo muy característico de nuestra Península, y, al mismo tiempo, contradictoriamente, se buscaba un origen foráneo.

Hace unos años, Pilar Acosta ya defendió el origen autóctono de los oculados, tras un detenido análisis de las representaciones de ojos soliformes sobre todo en cerámicas: «Por ahora, me limito a indicar que el reiterado uso de soliformes para la representación de los «ojos» en ídolos de tipología variada, muebles o rupestres, e incluso en cerámicas, es un aporte eminentemente indígena, de raíz neolítica, a las novedades del calcolítico, ya que en los ídolos orientales no se encuentra apenas dicho motivo decorativo y mucho menos para tal fín» (Acosta, 1984, pág. 48). Parece que sus sospechas se han cumplido, No sólo encontramos motivos aislados soliformes grabados en la cerámica de los sepulcros de fosa, sino una auténtica representación de un rostro femenino con los ojos figurados de esta manera.

Teniendo en cuenta las últimas dataciones aportadas por los descubridores de la pieza -aunque sea para el relleno de la mina 70 no para el pozo 16 en que se encontró- entre el 5090 y el 4660 B.P. (Bosch y Estrada, 1995, pág. 255), correspondería a un momento avanzado de la cultura, aunque la pieza ya estuviera amortizada. Es un primer indicio y, 
sobre todo, una clara advertencia de la importancia de las relaciones y contactos entre los distintos grupos Neolíticos/Calcolíticos a nivel peninsular - cosa que ya señaló Bosch Gimpera al relacionar los sepulcros de fosa con el área de Almería. Ahora, la Variscita Férrica de Can Tintoré, y el estudio de su dispersión, permite aproximarse con más seguridad a la amplitud de intercambios y relaciones de las gentes de los «sepulcros de fosa».

\section{BIBLIOGRAFIA}

Acosta Martinez, P., 1984: «El arte rupestre esquemático ibérico: Problemas de cronología preliminares"., en Sripta Praehistorica Francisco Jorda Oblata. Universidad de Salamanca, págs. 31-61.

ACtes I CONGRÉs del NeOlitic a la PEnínsula IBÉRICA. Formació i implantació de les comunitats agrícoles. Rubricatum 1 (2 vols.). Museo de Gavá, 1996.

AlCALDE, G. y otros, 1992: «Habitats al aire libre del Neolítico antiguo y medio del nordeste de Catalunya». En P. Utrilla (Coord), Aragón/litoral mediterráneo, págs. 335-343.

ANdRÉS RuIPÉREZ, T., 1992: «Relaciones Aragón-Litoral Mediterráneo. Sepulcros del Neolítico al Bronce». En P. Utrilla (Coord), Aragón/litoral mediterráneo, págs. 469-489.

BALDELLOU, V., 1992: «El Neolítico en Cataluña y sus relaciones con Aragón». En P. Utrilla (Coord.), Aragón / litoral mediterráneo, págs. 197-211.

Delibes de Castro, G., y M. Rojo Guerra, 1992: «Ecos mediterráneos en los ajuares dolménicos burgaleses». En P. Utrilla (Coord), Aragón / litoral mediterráneo, págs. 383-388.

Bosch, J. y EstRADA, A., 1995: «El Neolític Postcardial a les mines prehistòriques de Gavà», en Rubricatum, Revista del Museo de Gavà (Barcelona) № 0 , págs. 15-291.

Demoule, J-P., y Guilaine (Directorres), 1986: Le Neolithique de la France. Homage a Gerard Bailloud. Picard. París.


verdes en el nordeste peninsular durante el Neolítico». En P. Utrilla (Coord), Aragón / litoral mediterráneo, págs. 361-373.

Estat de la Investigació sobre el Neolitic a Catalunya. 1992, 9è. Coloqui Internacional d'Arqueologia de Puigcerdà, Puigcerdà y Andorra 1991. Centenari del naixement de P. Bosch Gimpera. Institut d'Estudis Ceretans, Andorra 1992.

Font, A., 1974: «Esqueleto neolítico de un sepulcro en fosa (El Bruch, Barcelona). Pyrenae 10, págs. $7-19$.

- 1980: «El complejo funerario neolítico de Sabassona (Vich, Barcelona). Avance al estudio de los restos humanos».Actas del I Congreso Español de Antropología, Vol. II, págs. 553564.

Fusté, M., 1952: Cráneos procedentes de la necrópolis de Sant Quirze de Galliners (Barcelona). Trabajos del Instituto «Bernardino de Sahagún», CSIC, vol XIII, n 1, Barcelona.

- 1960: «Estado actual de la antropología prehistórica de la Península Ibérica». En I Symposium de Prehistoria de la Península lbérica, septiembre de 1959. Institución Príncipe de Viana, Pamplona.

- 1963: “Antropología Prehistórica de la región catalana".l/ Symposium de Prehistoria Peninsular. Instituto de Arqueología de la Universidad de Barcelona, 1963.

- 1966: «Restos humanos prehistóricos de la cueva del Toll (Moià, Barcelona)» Pyrenae, Universidad de Barcelona.

Hommage à Jean ARnAL, 1988: Le Chasseen en Languedoc Oriental. Actes des Journées d'Etudes (Montpellier, 25, 26 y 27 de octubre de 1985). Universidad de Montpellier.

Marti Oliver, B., 1988: “Neolitico" En Prehistoria de la Península lbérica. Ariel, Barcelona, págs. 121-195.

Martín Colliga, A., 1982: "El Coll de Llinars del Vallès (Barcelona)». En Les Excavacions Arqueologicas à Catalunya. № I, Barcelona. 
- 1992a: «Dinámica del Neolítico antiguo y medio en Cataluña». En P. Utrilla (Coord), Aragón/litoral mediterráneo, págs. 319-333.

- 1992 b:»Estrategia y culturas del Neolítico final y Calcolítico en Cataluña». En P. Utrilla (Coord), Aragón / litoral mediterráneo, págs. 389-397.

Martín Colliga, A.; Guilaine, J., y ThommereT, J., 1981 » «Estratigrafía y dataciones de C14 de yacimiento de la Cova del Frare de Sant LLorens del Munt". Zephyrus XXXII-XXXIII. Universidad de Salamanca, 101-111.

- Y otros, 1988: "Campanya d' excavacions arqueologiques 1987-1988 al jaciment de la bóvila Madurell-Can Feu (Sant Quirze del Vallés)». Arrahona (Sabadell), 3, págs. 9-23.

Mercadal, O., 1988-89: "Estudi Paleoantropològic de l'individu 1 del «Clot de la Canaleta» (Roque d'Aguiló, Conca de Barberè, Tarragona». Separata del Butlletí Arqueològic, Época $\checkmark, n^{\circ}$ 10-11, págs. 47-63. Real Sociedad Arquelógica Tarraconense, Tarragona.

MESTRES, J.S., y MARTiN, A., 1996: «Calibración de las fechas radiocarbónicas y su contribución al estudio del Neolítico catalán». En I Congrés del neolític a la peninsula lbèrica. Formació e implantació de les comunitats agrícoles. Vol 2, págs. 791-804.

MuÑoz AmILIBIA, A Mª 1965 :La cultura neolítica catalana de los sepulcros de fosa. Instituto de Arqueología y Prehistoria, Universidad de Barcelona, "Publicaciones Eventuales» $n^{\circ} 9$.

- 1983: "Les comunitats neolítiques». En Història de Catalunya. Edit. Salvat, Barcelona, págs. 44-60.

- 1996: «El Neolítico en la Península Ibérica». En Unidades Didácticas de Prehistoria, Tomo II. UNED, Madrid, págs. 195-224.

- 1997: «El Neolítico final-Calcolítico en España y la Cultura de Ozieri». En La cultura di Ozieri. La Sardegna e il Mediterraneo nel IV e III millennio a.C. Atti del $2^{\circ}$ Convegno di Studi di Ozieri, 15-17 ottobre 1990, a cura di Lucrezia Campus. Presentazione di Giovanni Lilliu. Edizioni el Torchietto, Ozieri, págs. 185-205.

PHILLIPS, P., 1982: The Middle Neolithic in Southern France. Chasséen Farming and Culture process. BAR International Series, 142, Oxford.

Riuró Llapart, F., y Fusté Ara, M., 1980: Les estacions prehistoriques del Puig de'En Roca, Vol. II, Les necrópolis del Neolitic final de Sant Julià de Ramis i del Puig d'En Roca (Girona). Associació Arqueològica de Girona, Girona.

TARradelL, M., 1962: Les arrels de Catalunya. Edit. Vicens Vives, Barcelona.

UtRillla MiRANDA, P. (Coordinadora), 1992: Aragón / Litoral Mediterráneo:Intercambios culturales durante la Prehistoria. En Homenaje a Juan Maluquer de Motes. Institución Fernando el Católico, Zaragoza.

Villalba, Mà J., y otros, 1986: Les mines neolítiques de Can Tintorer, Gavà. Excavacions 19781980. Excavacions Arqueologicas a Catalunya, n 6, Departament de Cultura de la Generalitat de Catlunya, Barcelona

VILLALBA, M. $=$ J., y EDO, M., 1992: "Aspectes sobre la minería subterrània y la tecnología aplicada als sistemas de exploració». En Estat de la investigació sobre el Neolític a Catalunya, págs. 195-199.

VILLALBA, M‥J.; BAÑOLAS, L., y Edo, M., 1991: "Les ceràmiques decorades del complex miner de Can Tintorer relacionables amb les del Chassià meridional clàsic", en $9^{\circ}$ Coloquio Internacional de Arqueología de Puigcerdá, Institut d'Estudis Ceretans, Andorra. 